\title{
Measuring Workforce Preparation and Employment Outcomes
}

\author{
David Radwin and Laura Horn
}

Community colleges, the nation's largest provider of postsecondary education, enroll over 10 million students per year, many of whom seek an accessible and affordable option to prepare for employment or to upgrade their job skills. ${ }^{1}$ Community colleges play a pivotal role in providing training for "middle-skill-level" jobs-those that require a postsecondary credential below the bachelor's degree.

Since 2011, through the Trade Adjustment Assistance Community College and Career Training program, the US Department of Labor has funded more than $\$ 2$ billion in grants to more than 700 community colleges. These grants enable schools to develop training programs with employer and industry partners to fill local skills gaps and create programs targeted to emerging industries. As The New York Times columnist Thomas Friedman recently noted in an op-ed column highlighting these programs, "everyone wants employees out of college or technical schools who are as ready to plug and play as possible."2

Community colleges are poised to scale these initiatives. With so much invested, how do we measure the success of these programs? This brief addresses this question.

Because community college students enroll at least 40 percent of college undergraduates, measuring their employment outcomes is critical to assessing the success of US workforce development efforts.3(tablel.3) Yet a key challenge is linking college with employment outcomes. Colleges do not typically have regular contact with students after they leave for the workplace, so colleges must turn to administrative records and surveys to track students' employment outcomes.

\section{Key Findings}

- As the nation's largest provider of postsecondary education, community colleges are instrumental to workforce development, but measuring student outcomes is challenging after students have left for the workplace.

- Many states use existing administrative data such as unemployment insurance records to calculate employment outcomes at minimal marginal cost, often disaggregated by field of study and award type, but they miss certain segments of the workforce and are significantly limited in the detail they can provide.

- Surveys cover individuals not included in administrative data and collect other important details, but they are expensive to administer and may not yield results that can be reliably disaggregated by field of study or tracked over time.

- Ideally, community colleges would use both administrative record matching and surveys to provide a comprehensive measure of workforce preparation and employment success.

\section{Administrative Data}

The most common method of measuring employment outcomes, currently used by community colleges in more than 15 states, is to match student records to administrative data. The match is most often made to unemployment insurance (UI) data that are collected by states to administer unemployment benefits but are used by colleges to calculate annual earnings. 
Figure 1. Mean annual earnings after 1 year for graduates of associate's degree programs in Tennessee community colleges, overall and by selected field of study

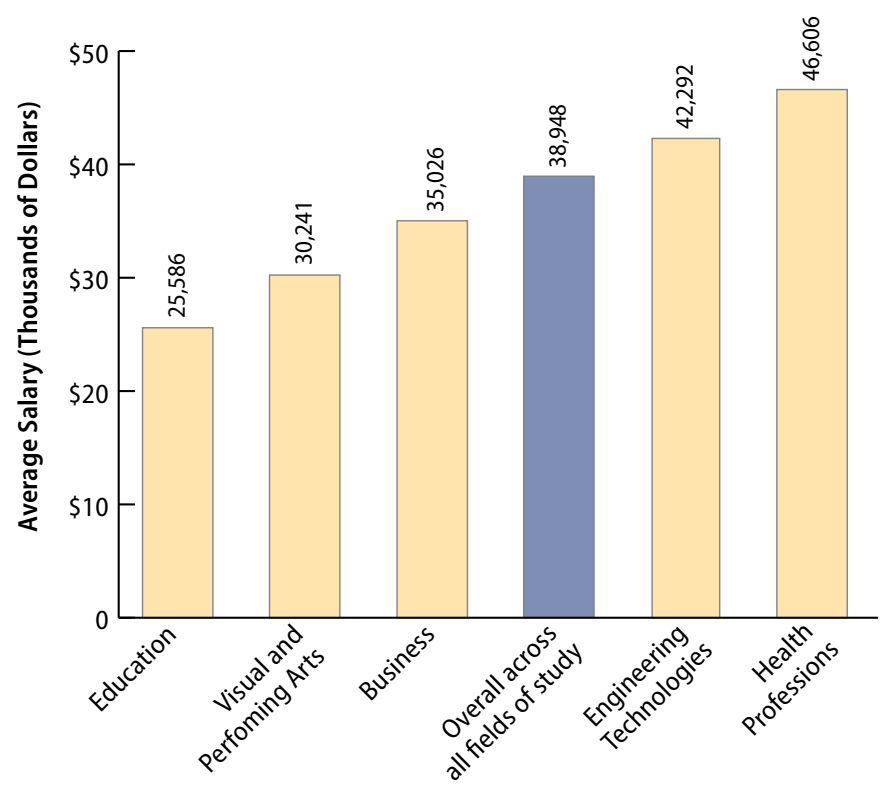

SOURCE: Schneider and Vivari, 6 p. 13.

Figure 2. Mean annual earnings after 1 year for graduates of certificate programs in Tennessee community colleges, by selected field of study

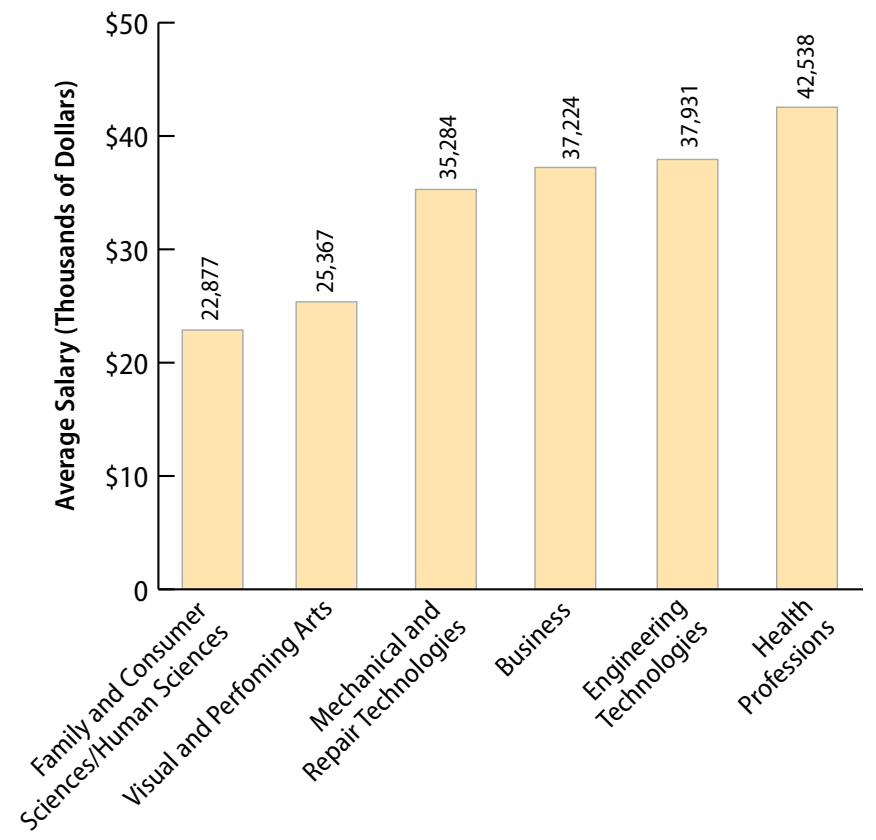

NOTE: Overall average earnings for certificate completers across all fields of study was not reported in source.

SOURCE: Schneider and Vivari, 6 p. 15.
Typically, colleges match the postsecondary records for a group of former students to UI data for a particular time period using Social Security numbers; discard results that appear to be incomplete (such as earnings for only part of a year) or not representative (such as students known to have reenrolled in postsecondary education); and calculate summary statistics such as median annual earnings 1 year after completing a certificate or degree. Some colleges also calculate employment rates from the proportion of students with earnings in a given time period. (Another use of administrative data for measuring workforce success, not elaborated upon here, is licensure exam passage rates for specific occupations such as cosmetology and nursing.)

The chief advantage of using UI data is the data system's availability. UI data are collected by states for administrative purposes, so the primary expense for creating measures of employment rates and wages is setting up the legal, bureaucratic, and data processing infrastructure required to match UI and student records. (Some states already routinely incorporate both postsecondary and UI data in their state longitudinal data systems, and others are beginning to do so.)

Once this step is achieved, the marginal cost per additional student is minor. Because employers and government agencies have a vested interest in correctly compensating employees, administrative data are widely assumed to be more accurate than equivalent self-reported data.,45 Moreover, the often large number of available records allows reporting by field of study, type of award, and institutional and student characteristics. For example, Figure 1 shows that Tennessee community college students who attained an associate's degree earned an average of $\$ 38,9001$ year after graduation, with these earnings ranging from $\$ 25,600$ for education majors to $\$ 46,600$ for health professions majors.

The Tennessee data also reveal substantial earnings differences by field of study for certificate completers (Figure 2). For example, after 1 year, Tennessee community college students who earned a certificate in family and consumer sciences/human sciences, which includes fields such as child care and consumer merchandising, earned an average of $\$ 22,900$, compared with an average of $\$ 35,300$ for those who earned a certificate in business and $\$ 42,500$ for those who earned a certificate in health professions. ${ }^{6}$ 
The chief disadvantage of UI data is that they are collected for transactional purposes, which lack many of the valueadded characteristics of data collected specifically for research purposes. ${ }^{7}$ Most prominently, state UI records do not cover certain large categories of workers, such as federal and military employees, out-of-state employees, and the selfemployed. Also, job placement rates based on UI data cannot exclude individuals who are not looking for work for such reasons as continuing their education or raising children, so these statistics tend to understate the true employment rate.

\section{Surveys}

The main alternative to UI data is employment surveys, which reach former students including those missed by UI data: federal and military employees, out-of-state employees, and self-employed individuals, and which can exclude individuals not looking for work. Surveys also collect important employment-related details not usually included in administrative records, such as full-time or part-time employment, number of jobs held, industry type, and job title and occupational classification. Survey data can also collect information on key benefits, such as the availability of employer-sponsored health and retirement benefits.

Other job-related value indicators that surveys can capture include licensing status for any occupation and subjective factors such as job satisfaction, perceived job security, and perceived opportunities for advancement. These additional details can provide a fuller and more nuanced portrait of community college students' success in the workplace. Multiyear longitudinal surveys, which interview individuals multiple times, can add even more context such as students' initial educational and career goals and expectations while they are still enrolled, changes in their employment status, and additional education and training after leaving community college. 8,9

The primary drawback to employment surveys is that they tend to cost a lot more to reach far fewer individuals, especially if administrators seek the high response rate widely believed to be necessary for accurate results (Seastrom ${ }^{10}$; but see Radwin ${ }^{11}$ ). Because of the expense of tracing, contacting, and gaining cooperation from former students, such surveys are limited to samples rather than populations, which in turn reduces the precision and usability of estimates and may preclude disaggregation by field of study or award type.

\section{Recommendations and Conclusions}

A subset of the growing number of community colleges reporting earnings based on state UI records are incorporating data from other administrative sources to partially fill gaps in coverage of earnings. Community colleges in several states collect UI data from neighboring states or from the federal Wage Record Interchange System to include workers employed out-of-state. Elsewhere, community colleges use data from the state tax authority to include federal employees and self-employed individuals within the state.

Although how community colleges measure workforce preparation and employment outcomes (if indeed they do so at all) will be guided by the resources available to them, the ideal approach would combine both administrative and survey data. Administrative record matching provides earnings data for a population large enough to disaggregate by field of study and for a sufficient timespan to track students' wages over multiple years. Surveys target a representative sample of former students to reach those not included in available administrative records and to measure key employment characteristics such as job titles and industry classifications, full-time or part-time employment, and the prevalence of employer-provided health, retirement, and other fringe benefits. As one example of combining both data types, the Washington State Board for Community and Technical Colleges ${ }^{12}$ uses survey data to estimate the percentage of former students who do not appear in UI data because they are self-employed or employed out-of-state.

Regardless of how community colleges measure the employment outcomes of their students, job placement rates and earnings statistics are strongly influenced by local and regional economic conditions, such as variation in employer demand and wage differences due to the cost of living. Colleges conferring many awards in higher-paying health and engineering fields would appear to have students earning more, on average, than those colleges with a large proportion of graduates in less lucrative arts and education fields, even if within each field the graduates of each state had identical earnings. Students' choices of degree program and field of study are largely out of the control of community colleges, and employment measures that do not account for these differences will not accurately reflect how well prepared the students are for the workplace. 


\section{References}

1. Ginder SA, Kelly-Reid JE, Mann FB. Postsecondary institutions and cost of attendance in 2013-14, degrees and other awards conferred, 2012-13, and 12-month enrollment, 2012-13. Washington, DC: National Center for Education Statistics, Institute of Education Sciences, US Department of Education; 2014.

2. Friedman T. It takes a mentor. New York Times. 2014 Sep 9:A27.

3. Skomsvold P. Web tables: profile of undergraduate students: 2011-12. Washington, DC: National Center for Education Statistics, Institute of Education Sciences, US Department of Education; 2014.

4. Dudley KM. Use of administrative records in NCES secondary and postsecondary sample surveys. 2012 Federal CASIC Workshops. Washington, DC; 2012.

5. Hotz VJ, Goerge R, Balzekas J, Margolin F, eds. Administrative data for policy-relevant research: assessment of current utility and recommendations for development 1998. Chicago: Northwestern University/University of Chicago Joint Center for Poverty Research. Retrieved 2014 Oct 10 from http://econ.duke. edu/ vjh3/working_papers/adm_data.pdf

6. Schneider M, Vivari B. The earning power of graduates from Tennessee's colleges and universities: how are graduates from different degree programs doing in the labor market? Washington, DC: College Measures; 2012. Retrieved 2014 Oct 10 from http://collegemeasures.org/file.axd?file=Earning_Power_ TN_Graduates_Sept12.pdf

7. Groves RM. Three eras of survey research. Public Opin Q. 2011;75(5):861-871.

8. Hoachlander G, Sikora AC, Horn L. Community college students: goals, academic preparation, and outcomes. Washington, DC: National Center for Education Statistics, Institute of Education Sciences, US Department of Education; 2003.

9. Ifill N, Radford AW. Web tables: beginning subbaccalaureate students' labor market experiences: six years later in 2009. Washington, DC: National Center for Education Statistics, Institute of Education Sciences, US Department of Education; 2012.
10. Seastrom MM. NCES statistical standards. Washington, DC: National Center for Education Statistics, Institute of Education Sciences, US Department of Education; 2012.

11. Radwin D. High response rates don't ensure survey accuracy. Chronicle of Higher Education; 2009 Oct 5.

12. Washington State Board for Community and Technical Colleges. Data linking for outcomes assessment 2012-13. Retrieved 2014 Oct 10 from http://www.sbctc.edu/college/it/DLOA_2012-13.doc

\begin{abstract}
About the Authors
David Radwin, a senior research associate in the Center for Postsecondary Education at RTI International, is the lead analyst for The Completion Arch ${ }^{\mathrm{TM}}$, a web-based resource that provides quick and easy access to national-, state-, and initiative-level data that describe the progress and success of community college students. He also contributes to data collection, processing, and analysis for multiple studies of postsecondary students, under contract to the National Center of Education Statistics (NCES) in the U.S. Department of Education.
\end{abstract}

Laura Horn, director of RTI's Center for Postsecondary Education Research, is an expert in postsecondary education research and policy related to student progress and success. For nearly two decades, under contract to NCES, she has directed numerous studies and written extensively about postsecondary student experiences and outcomes, often focused on students historically underrepresented. Over the last decade, she has built a research agenda focused on community college student success. Ms. Horn conceived of and currently directs The Completion Arch ${ }^{\mathrm{TM}}$ for RTI.

RTI Press Research Briefs and Policy Briefs are scholarly essays on policy, methods, or other topics relevant to RTI areas of research or technical focus.

RTI International, 3040 East Cornwallis Road, PO Box 12194

Research Triangle Park, NC 27709-2194 USA

$919.541 .6000 \quad$ rtipress@rti.org www.rti.org

○2014 Research Triangle Institute. RTI International is a registered trademark and trade name of Research Triangle Institute.

All rights reserved. This brief is protected by copyright. Credit must be provided to the author and source of the document when the content is quoted. Neither the document nor partial or entire reproductions may be sold without prior written permission from the publisher.

RTI Press publication PB-0005-1410

http://dx.doi.org/10.3768/rtipress.2014.pb.0005.1410 www.rti.org/rtipress 